John Heeley

Best Destination Marketing and Sheffield Hallam University, UK

johnheeley@bestdestinationmarketing.com

UDC: 338.487:659.1

\title{
MARKETING EVERYTHING AND THEMING SAMENESS - URBAN DESTINATION MARKETING IN CONTEMPORARY EUROPE
}

\begin{abstract}
This paper reviews the academic and practitioner literature on urban destination marketing, suggesting that it contains within it a dominant paradigm which the author characterises as 'the theory of marketing competitive advantage'. As such, this theory requires towns and cities to differentiate themselves through the provision of unique products, based on which they subsequently undertake branding, market positioning, distribution and other activities through bespoke destination marketing organisations (DMOs). Practice is then contrasted with theory by reference to a discordant strand of the literature as well as the actual destination marketing currently being undertaken in 60 European towns and cities. The theory of marketing competitive advantage is shown to be an ideal which rarely translates into practice. Irrespective
\end{abstract}

\section{Introduction}

"I gotta talk honest...we have a big problem.... We did an experiment in our offices a couple of weeks ago.... We cut out the ads for every single North American destination we could find.....and you know what? You can't tell the difference between one and the other.....All of the ads are exactly the same....every destination shows the same thing - the United States of Generica. We are becoming so much like our neighbours there's no reason to travel.... How do we differentiate our destinations? of whether or not a town or city possesses competitive advantage, DMO destination marketing gravitates almost inexorably towards a "marketing of everything". Such an approach, in turn, reduces to a bland and monolithic "theming of urban sameness", all of which is diametrically opposite to what one would expect to be the case as per the theory of marketing competitive advantage. The author contends that this gap between theory and practice matters, necessitating a rethinking of how academics and practitioners should in future seek to explain or otherwise account for urban destination marketing.

Key words: urban destination marketing, competitive advantage, differentiation, destination branding, destination marketing organisation.

Author and brand management consultant Bruce Turkel, addressing North America's visitor and convention bureaux, 2012 annual convention of the Destination Marketing International Association, July 16-18, 2012, Seattle

This paper's central tenet is that urban destination marketing in contemporary Europe is 'much of a muchness'. While the paper's geographical focus is Europe, as the "United States of Generica" quip above indicates, 'much of a muchness' in urban destination marketing is a global issue. As a general rule, the marketing approaches pur- 
sued by destination marketing organisations (DMOs) and the materials produced by them are strikingly similar both in form and content. While some convergence in respect of form is to be expected (amongst towns and cities there is a more or less standard DMO marketing template), uniformity of content is surprising, bordering on astonishing, given that academics and practitioners subscribe overwhelmingly to the view that urban destination marketing is quintessentially a process of differentiation based on competitive advantage. The latter view in effect represents a paradigm through which the world of urban destination marketing is made sense of by academics and practitioners alike. As such, I think it is fair to say that it constitutes a mantra. I will henceforth in this paper refer to this paradigm come mantra as the theory of marketing competitive advantage (CA).

So it is that having been a DMO chief executive officer (CEO) for over twenty years (1990-2011), the author now finds himself in the rather curious and somewhat embarrassing position of debunking (at least partially) the very theory of which he had been for so long such an enthusiastic and earnest supporter. Ironically, one of my last tasks as the outgoing CEO of European Cities Marketing was to organise a seminar in March 2011 held in Sofia for which I recruited as keynote speaker, Eddie Friel, a much respected tourism consultant and former head of the DMO for Glasgow. His address in the Bulgarian capital represented in limpid, unadulterated form the theory of marketing CA. In it, he referred to DMOs as the "champions" of cities, and to their marketing "competitive difference" as enshrined in distinctively "powerful narratives" (Friel, 2011). Piling on the irony, it had been Eddie - sometime back in the early nineteen eighties - who had introduced me to what I am now calling the theory of marketing CA when I was a tourism lecturer in Glasgow at Strathclyde University!
This paper is in two parts. The first sets out the theory of marketing competitive advantage as it took root towards the end of the last century to become in the new Millennium a prevailing orthodoxy come mantra. It introduces 'the Johnson test' as a way of clarifying the concept of competitive advantage as this relates to urban destination marketing. Moving from theory to practice, the second part examines towns and cities from the vantage point of whether or not they have a genuine, critical mass of competitive advantage in tourism; characterising the content of destination marketing in both 'have' and 'have not' situations as a 'marketing of everything' approach. Taking into account the forces of globalisation, this equates to a bland and ubiquitous 'theming of urban sameness', more or less the exact opposite of what we would expect to happen as per the theory of marketing CA. This gap between theory and practice matters, and warrants reappraisal of the theory of marketing CA as it has been applied to urban destination marketing.

\section{Theory: marketing competitive advantage (CA)}

Urban destination marketing as per the theory of marketing competitive advantage runs like this:

- On the product/supply side, a town or city identifies and/or creates unique selling propositions (USPs) with which to differentiate it in the tourist marketplace; as such, uniqueness and differentiation lie at the heart of the theory of marketing CA. They form the 'what' of urban destination marketing.

- On the basis of uniqueness and differentiation, the DMO then positions the town or city and distributes its various offers to targeted audiences, undertaking media relations, travel trade liaison, promotion and advertising (below and 
above the line/offline and online), making it easy for the customer to purchase products ahead of and during his/her visit. These activities constitute the 'how' of urban destination marketing.

As per the above 'what' and 'how' model, the rationale for a DMO undertaking urban destination marketing is the creation of visitors from whose spending the town or city derives commercial and economic benefit. As such, the theory of marketing CA as applied to urban tourist locations is deceptively logical and straightforward; so much so that it can and does appear as unproblematic, obvious and required.

The origins of the theory of marketing $\mathrm{CA}$ as it relates to tourism doubtless stretch well back in history, but a useful if perhaps somewhat unusual starting point with which to clarify the concept is to be found in James Boswell's Life of Samuel Johnson which records this conversation as having taken place on Tuesday $12^{\text {th }}$ October 1779 :

"BOSWELL. Is not the Giant's-Causeway worth seeing?

JOHNSON. Worth seeing? Yes; but not worth going to see." (Boswell, 2008:744)

Here is a classic statement of CA applied to tourism and travel. Johnson is conceding that the Giant's Causeway (a striking coastal rock formation on the northern tip of Ireland) has some touristic value, but from his standpoint this was insufficiently compelling to warrant a visit, especially when set alongside the cost and inconvenience to which this would also give rise. In this sense, all tourist destinations may be evaluated in respect of whether or not they possess a genuine, critical mass of competitive advantage; what I will henceforth refer to as 'the Johnson test'.

Manifestations of the theory of marketing CA as the cornerstone of urban destination marketing are evident in practitioner and academic circles from at least the nine- teen eighties onwards. For instance, a practitioner case in point is a study of Glasgow's tourism potential completed by the consultants Pannell Kerr Forster (PKF) in 1983. It concluded that at that particular point in time the city's "product profile did not meet the requirements of Scotland's 'traditional tourist' " who instead made a beeline for the attractions of Edinburgh and the Highlands and Islands (Friel, 1989: 76). In other words, Glasgow at that time lacked USPs and CA. In the light of this assessment, PKF's report provided the newly formed DMO for Glasgow (the Greater Glasgow Tourist Board and Convention Bureau) with a strategy; in the short to medium term it should seek to attract 'footloose' cultural events (later on in that decade it bid successfully to stage European Capital of Culture) while encouraging over the longer term a sustained and expansive development of competitive advantage in respect of new and/or refurbished visitor attractions (Heeley, 2011: 39-44). An example of the theory of marketing competitive advantage as it was crystallising in academic minds is illustrated by a tourism marketing and management handbook published towards the end of nineteen eighties (Witt, 1989); in this text, Pearlman emphasised the need for destinations to concentrate on "those products which have unique appeal" (Pearlman, 1989: 11), while Middleton defined "destination attractions" as "the elements within the destination's environment which, individually and combined, serve as the primary motivation for tourist visits" (Middleton, 1989: 573).

During the nineteen nineties, the theory of marketing competitive advantage as the basis of urban destination marketing gathered significant momentum as an academic perspective. In The Tourist Gaze, for instance, John Urry argued that tourists seek out differences, directing their attention to more or less unique features of culture, heritage, and landscape which are divorced from their own everyday experience; places, 
he opined, were relatively substitutable so that in competing for customers it was imperative that destinations should major on images grounded in uniqueness and therefore competitive advantage (Urry, 1990). In the same year as The Tourist Gaze was published, Gilbert drew on marketing principles to suggest that countries and their national tourist organisations should differentiate themselves in respect of market positioning (Gilbert, 1990). In Selling Tourism Places, Goodall asserted that tourist destinations could be branded, distributed and sold in much the same way as any commercial commodity (Ashworth and Goodall, 1990). The tourist, he said, purchases a resort because it represents value for money in the form of a "superior place product" i.e. the resort has competitive advantage on the supply or product side of things (ibid: 259). The trick, according to Goodall, was successfully to link together "place product marketing and the tourist's holiday choice process" (ibid: 261). In a similar vein, another text saw the twin challenges facing destination marketers as being identification of "the resort's special advantages" and understanding of "how to entice those visitors which the destination hopes to attract" (Laws, 1995:113). Writing specifically about towns and cities, Stephen Page in Urban Tourism depicted destination marketing as “...promoting the place's values so that potential users are fully aware of the place's distinctive advantages" (Page, 1995: 208).

Arguably the seminal statement of the theory of CA as applied to urban destinations in the nineteen nineties is Kotler's Marketing Places: Attracting Investment, Industry, and Tourism to Cities, States and Nations. Its core idea was that towns and cities were increasingly competing with each other "to attract their share of tourists, businesses, and investment" (Kotler et al, 1993: 21). DMOs were tasked with undertaking a comprehensive "place audit" in which strengths, weaknesses, opportunities and threats could be identified via a SWOT analysis (ibid: 81 ). The audit enabled a destination to assess "economic/demographic characteristics" and "sort them into competitive strengths and weaknesses"; after this, the DMO then undertook the actual marketing of "place advantage" (ibid: 81, 215). In this and later texts, Kotler's direct and easy to understand commands were: select, choose and communicate (Kotler, 1997) viz. identify a set of possible competitive advantages, select one, and then effectively communicate it to target audiences. His work was to prove most influential in urban destination marketing in respect of strategy and policy formulation, as well as in shaping the thinking of academics.

These early, pioneering writings on the theory of marketing CA were all published in the last two decades of the twentieth century, corresponding to a period when tourism had become an academic growth industry (Heeley, 1982) as well as something to which towns and cities in Europe were increasingly turning their attention (Heeley, 2011: chapter 1). Former industrial centres were seeking to boost and regenerate their flagging economies (Laws, 1992), while in so-called 'heritage towns' and in capital cities, there was a growing recognition that purposeful urban management required a more holistic and resident-centred treatment of tourism, so as to minimise disbenefits as well as maximise employment and turnover gains (Heeley, 1987).

Into the new Millennium, academic and practitioner perspectives coalesced around the theory of CA, with further refinement in the literature of the marketing processes and techniques with which it was associated, notably destination audit/SWOT analyses, differentiation, segmentation, destination competitiveness and branding, market positioning, and promotion/ distribution. In 2000, for instance, Buhalis exhorted destinations to differentiate their products by emphasising their uniqueness. Alluding to 
the latest internet and web-based technologies, he suggested DMOs now had greatly enhanced capabilities with which to deliver differentiated tourism products (Buhalis, 2000). A paper by Kavaratzis and Ashworth on city branding conceptualised the process as a differentiation of both product and consumer (Kavaratzis and Ashworth, 2005), while Simon Anholt and others proselytized the wider notion of destination branding, depicting success in this field as a process of exploiting competitive identity (Anholt, 2007). In a book bearing that title, Anholt singled out tourism as the single most important way - the most powerful of six "booster rockets" - with which a nation or locality could market itself to become 'known' and hence prosper (ibid: 88-91).

Kolb in Tourism Marketing for Cities and Towns set out the process of urban destination marketing in manual form (Kolb, 2006). Strategically, this began with identification of the "unique characteristics" of a town or city, followed by the packaging of these so as to effectively market the place as "truly unique" (Kolb, 2006: 14). Tactically, an urban destination had to segment the market, brand the destination, and position its product (ibid: 16-23, 228-229). Segmentation, Kolb said, profiled the potential consumer, while branding involved "promoting the unique benefits that the tourist will experience" (ibid: p. 18). As such, the brand should be "incorporated into all the promotional material created by the city" (ibid: 23). Working along the grain of the destination brand, positioning referred to "how the consumer differentiates between similar products" and, as such, "answers the consumer's question of why the city is unique" (ibid: 228). Positioning, in turn, was based on the "core product" or USP identified in the destination audit or SWOT analyses: for a town or city these could range from a "unique botanical garden" to a flagship sporting or cultural event, through to its "fall foliage" or the "superior quality" of its customer service (ibid: 228-229).
A characteristic twenty first century statement of the marketing of CA in respect of destination marketing is Pike's Destination Marketing: an integrated marketing communications approach, a 'cross-over' text written by a tourism practitioner turned academic (Pike, 2008). His starting point is the competitive tourism marketplace which "forces DMOs at all levels to develop effective differentiation strategies" (ibid: 116). In such a context, the DMO itself becomes reducible to competitive advantage:

"A successful strategy achieves a point of difference against competitors on an attribute deemed important by the market. A DMO's resources consist of sources of comparative and competitive advantage" (ibid: 132).

In a similar vein, Morgan and Pritchard in Destination Branding: creating the unique destination proposition posited a dialectical relationship between differentiation, on the one hand, and rising consumer expectations and industry standards on the other. The latter served to make differentiation ever more critical in a context of competing destinations in which nearly all could lay claim to having "a unique culture, landscape and heritage", "high standards of customer service and facilities" and "the friendliest people" (Morgan et al, 2008: 60). Other contributors to this text echoed the need to assemble and implement an unsurpassable destination brand which competitors could not emulate, presenting destination marketing case studies in which fine-tuned differentiation was exemplified. For example, a chapter by the then marketing director of the Wales Tourism Board (Roger Pride) applauds "the quest for true differentiation", belittling "imitation and copycat strategies" (ibid: 161). The golf as it should be campaign Pride instances illustrated how his DMO were differentiating this particular product by reference to fun (Wales), seriousness (Scotland), corporateness (England) and booziness (Ireland). 
Journal articles are nowadays redolent with the theory of CA as the basis of successful destination marketing. Though ostensibly "redefining tourism promotion", one such piece turns out to be a restatement of the theory of CA; it sets the familiar context ("the flooded market of locations and destinations") with the equally familiar prescription to differentiate on the basis of uniqueness:

"To be a success ... a city brand needs to be a unique and identifying symbol, a trademark that serves to differentiate competing products, services and places." (Paskaleva-Shapira, 2007: 112)

Another journal article - this time on best practice in regional scale destination marketing - reiterates the mantra in Kotleresque fashion, stating that destination marketing is grounded in the articulation of a "region's unique points" which serve to "set the region apart from its competitors" (Cox and Wray, 2011: 531, 528). This, in turn, is "central to the entire framework of best marketing practices for a regional destination" (ibid: 534). The "ultimate requirements of a successful destination marketing strategy is for the region to be able to present a unique identity to potential visitors" (ibid: 528).

As in academe, the dominant twenty first century practitioner perspective on urban destination marketing is the theory of marketing CA. For example, an edition of the e-newsletter DMO World included a master class on destination marketing, with a central message of "competitive superiority through differentiation" (DMO World, 2005). It cited the small town of Barrie in Ontario as having successfully positioned itself on the back of a huge shopping mall majoring on brand name discounting. In an account of the Incredible India destination marketing campaign, the then head of India's national tourist organisation (Amitabh Kant) could acknowledge the pioneering writings of Kot- ler while lauding the campaign for its having "differentiated India as a tourism destination based on its inherent strengths", using icons as diverse as curry, elephants and tigers, and the Taj Mahal (Kant, 2009). Finally, a pristine practitioner statement of marketing CA appeared in a handbook published in 2005 by the International Association of Convention and Visitor Bureaux (now the Destination Marketing International Association). Put simply, the guiding principles of successful destination marketing were to "sell your strengths" and "focus on amenities not found in competing destinations" (IACVB: 31).

As demonstrated above, the theory of marketing competitive advantage as an academic and practitioner perspective within which to explain and otherwise account for destination marketing now occupies centre stage. While its mainstream, hegemonic position has never to the best of my knowledge been challenged explicitly, with the benefit of hindsight we can see that from around the midpoint of the nineteen nineties onwards a handful of academic and practitioner commentaries reported findings and made recommendations which were manifestly at odds with the theory of marketing CA. For example, Judd's survey of U.S. cities remarked upon the difficulties faced by them in constructing appropriate destination imagery, observing how few places possessed iconic USP attractor such as the Eiffel Tower (Judd, 1995). Cities "that lack image cannot easily be promoted to tourists", he said, observing that DMO promotional efforts were typically and somewhat bizarrely majoring on the attractiveness of their rural backdrop and/or on a rather fluffy and nebulous set of imagery he characterised as the "nostalgic city of the past" (Judd, 1995:117). In a detailed content analysis of the destination marketing materials produced by four provincial cities in northern England (viz. Birmingham, Manchester, Sheffield, and Stokeon-Trent), Bramwell and Rawding noted 
that while there were "significant differences" in the imagery contained within guides and brochures, differentiation had strict limits (Bramwell and Rawding, 1996). The authors highlighted repeatedly used messages evident across all four cities: they "all used the big city imagery of exciting, lively, and cosmopolitan... with lots to see and do, together with up-beat, confident messages that they are dynamic and culturally enlivened (ibid: 208).

At the turn of the new Millennium, Swarbrooke suggested that urban authorities had often utilised tourism as a tool of economic and social regeneration "almost as a last resort", accusing them of taking an "uncritical view" of tourism's alleged economic benefits (Swarbrooke, 2000: 271, 277). At back of this, Swarbrooke pointed to a failure rigorously to assess whether or not a town or city really had a foundation of genuine competitive advantage on which to market itself effectively as an urban tourist destination:

"Many towns have spent money on trying - unsuccessfully and unrealistically - to establish themselves as tourist destinations... there is a need for realism, a need by decision-makers to realise when tourism is not a viable option for a town or city" (ibid: 278, 282).

A text by Christopher Law - Urban Tourism: the visitor economy and the growth of large cities - queried whether urban destinations could successfully be branded in the same way as ordinary commodities (Law, 2002). He also claimed that in reality the content of destination marketing was rarely determined by a systematic and rational assessment of competitive advantage, claiming a "package of elements is put together by promotion agencies.... on the basis of intuition rather than market research (Law, 2002: 54). Gilbert, writing on destination marketing in a student text entitled Tourism: Principles and Practice makes the telling point that DMOs "have to be even-handed in their support for businesses" because "it is difficult politically for them to back product winners" (Cooper et al, 2008: 612). He also goes on to make the throw away point that much DMO marketing had to date been "elementary." (ibid: p.613). Echoing Law, some commentators (the author included) are lately suggesting that few urban destinations are able successfully to implement city branding projects because the process is so tortuous and misunderstood, and because the policy instruments are inherently weak and constrained (Heeley, 2011: chapters 7 and 8). Indeed, the editors of City Tourism: national capital perspectives state flatly that urban complexity and fragmentation "inhibits developing a cohesive and unique brand..."(Maitland and Ritchie, 2009: 268) with case studies in this volume on Brussels and Budapest amply demonstrating the point, (ibid: 142-158, 201-12). In the previously mentioned account of the golf as it should be marketing campaign, the author (Roger Pride) concedes that "the majority of destinations still struggle to differentiate their offer from the competition" (Morgan et al, p. 160). In a recent journal article reporting on the findings of a content analysis of urban destination marketing materials, the author expresses his surprise at their uniform content: "Given the difference of cities, it is astonishing to discover that cities' tourism promotion materials repetitively use similar slogans, phrases and expressions" (Uysal, 2013: 17). Uysal's comment mirrors that of the destination branding consultant, Bruce Turkel, as reproduced in the title quote introducing this paper.

From Judd through to Uysal and Turkel, discordant notes have therefore been struck in respect of the theory of marketing CA as applied to urban destinations, albeit these have been sporadic and arguably at the margins of academe and practice. Clearly, urban destination marketing as per the theory of $\mathrm{CA}$ is at odds with a world in which the 
majority of urban destinations lack genuine competitive advantage, where the content of marketing materials is strikingly similar, where political even-handedness precludes 'backing winners', where rigorous audits and SWOT analyses are by and large absent, where destination branding is problematic, and where by implication public as well as private industry monies are being wasted. Valid and thought-provoking as they are, it is worth reiterating that the observations of Judd et al have at no point challenged the theory of marketing competitive advantage as a dominant paradigm within which to account for urban destination marketing. As such, they are best viewed as providing groundwork for the development of a new and significantly modified perspective. As the next section demonstrates, such a perspective is needed precisely because the theory of marketing competitive advantage bears such a slight and fitful relationship to practice 'out there' in the real world of urban destination marketing.

\section{Practice: marketing everything and theming sameness}

Three years ago in Inside City Tourism, I referred en passant to the gap between the academic literature on urban destination marketing and the manner in which it is actually undertaken by practitioners (Heeley, 2011: xix). Without then being able to put my finger upon why and how, it seemed to the author that academic writing on the subject conjured up an essentially different world to the 'real life' one inhabited by practicing urban destination marketers. Since leaving my CEO post at European Cities Marketing in 2011, the gap between the theory and practice of urban destination marketing has come into ever sharper focus on a personal front, as a result of my having undertaken teaching on a number of undergraduate and postgraduate destination marketing mod- ules. This has inevitably obliged me to familiarise myself with the considerable academic literature on urban destination marketing (it hardly existed when I left academe in 1990). Eventually there came a 'light-bulb' realisation that the theory of marketing competitive advantage as contained within that literature fell well short of 'telling like it is'. For the remainder of this paper, I present the bare bones of my new and revised thinking; not only on the nature and extent of 'the gap' between the theory and practice of urban destination marketing, but also on the related and more important issue of why this matters.

In practice, few DMOs adhere to the principles of differentiation and marketing of competitive advantage which, as we have seen, are central to academic treatises on urban destination marketing and to practitioner rhetoric. In support of this statement, I can draw upon my experience as a DMO chief as well as researches undertaken for my forthcoming book Urban destination marketing in Contemporary Europe: theory and practice which is scheduled for publication this summer. Table 1 summarises DMO marketing practice undertaken in 60 European towns and cities with which the author is familiar. Contrary to what one would expect to happen under the theory of marketing CA, the vast bulk of these urban destinations promote a remarkably standardised set of messages and symbols. Moreover, in addition to marketing content (the 'what' of urban tourism marketing), a sizeable gap is discernible between how the academic literature portrays DMOs undertaking their marketing, and how they in fact do it (the 'how' of destination marketing); from the manner in which audiences are targeted to the destination brand platforms they fashion and utilise, through to how outcomes are appraised. In short, all the academic texts and articles which form the received stock of wisdom and knowledge I have chosen to label as the theory of marketing CA bear little 
or no resemblance to the everyday world of urban destination marketing.

To an extent this gulf between theory and practice is reducible to the theory of marketing CA being normative (i.e. this is how urban destination marketing should be done), with practice being the more or less imperfect implementation of the associated principles and procedures. We might well expect academics to be unaware of the realities of DMO implementation (however perfect or imperfect this may be); after all, academic accounts of urban destination marketing are nearly always concocted from the outside; in the main academics do not participate in policymaking for urban destination marketing nor do they help shape its day-to-day execution. Much the greater part of scholarly writing on urban destination marketing is therefore grounded neither in experience nor empirical observation. As a consequence, principles and procedures advanced in conventional academic descriptions are often from a practitioner perspective impractical and/or irrelevant and/or outmoded and/or are done tokenistically (e.g. SWOT analyses, market positioning and segmentation). In ways which can only be conveyed by 'real life' experience, urban destination marketing is less a science and more the art of the possible; as such, pragmatism, opportunism, expediency, and compromise loom large, and are major factors determining the scope and content of the destination marketing being undertaken. The impact of politics (big ' $\mathrm{p}$ ' and little) should never be underestimated. One academic alludes to these realities in an account of his tenure as a board member of a regional level DMO, Welcome to Yorkshire (Thomas, 2011).Though "constrained from reflecting openly" (ibid: 497), he questions the unevidenced and seemingly irrational manner in which large amounts of public money were being used to attract events to Yorkshire whose local economic impact was highly questionable, notably Royal Ascot staged at York and the International In- dian Film Academy Awards held in Sheffield (Thomas, ibid: 498).

That said, the greater part of implementation in destination marketing departs from theory for reasons other than the normative one and the fact that academics and practitioners by and large inhabit separate worlds. First, the majority of towns and cities do not have a critical mass of competitive advantage; an inherited base of attractiveness either does not exist and/or has not been created. In Johnsonian parlance, the destination is 'worth seeing, but not worth going to see'. A rigorous 'Johnson test', however, is seldom applied in practice, and in any case it is self-evidently difficult for the leadership of a town and city to accept that as a place they haven't 'got what it takes' to compete as a tourist destination. This is affirmed by Ashworth; because of their natural and self-interested commitment to place, he points out that DMOs and local politicians and officials "are in a poor position to evaluate the place product effectively", while the ostensibly 'independent' consultants hired by them are all too "likely to concur" with the view that the town or city in question has 'got what it take' and can somehow or other find a niche for itself in tourism (Ashworth, 2011: 252). In this way, despite failing in reality to pass 'the Johnson test', countless towns or cities establish a destination marketing organisation which, in turn, puts in place the standard DMO marketing template of website, press visits, travel trade familiarisation trips, off and online advertising, social media pages, information centre, commercial membership scheme, convention bureau department, and so on and so forth. Lacking a genuine, critical mass of competitive advantage, a DMO thus established is obliged to pursue an approach which is the antithesis of marketing CA, with content honing faute de mieux upon anything and everything which is remotely attractive. This 'marketing of everything' approach is underscored 
by the powerful realpolitik organisational considerations referred to in the paragraph directly below. Importantly, in towns and cities 'worth seeing but not worth going to see', the logical implication is that destination marketing will ultimately always fail to realise its core purpose, because the fundamental competitive advantage on which to attract visitors and their resultant spending and economic impact is lacking.

Secondly, and on the surface paradoxically, in those destinations with CA (places which pass 'the Johnson test' and are 'worth seeing and worth going to see'), DMO marketing generally fails to emphasise it! Here once again, a 'marketing of everything' approach obtains, with the approach one of inclusiveness, covering all the amenities and services of the place (USPs included). Realpolitik considerations contribute to the failure to major on CA and USP. Destination marketing, as Fyall and others quite rightly depict it, is fundamentally a collaborative, partnership exercise; a bringing together of multiple public and private sector stakeholders across governance, strategy and operation (Fyall, 2005). In such a policy and organisational context, DMO marketing content nearly always gravitates away from competitive advantage to reflect the diverse interests and 'payback' requirements of all the stakeholders (Heeley, 2011: 82-83). In this way, guides, brochures, advertisements and videos become all-embracing and lowest common denominator, as opposed to concentrating on a single or small number of USP attractors. 'Payback' is reinforced by financial realities of the 'he who pays the piper calls the tune' variety. With DMOs increasingly obliged to exploit earned and private sector funding streams, mainly through commercial and corporate membership schemes (Heeley, 2011, pp. 90-91, 95-96), it self-evidently becomes ever more difficult for DMO marketing to be shaped by USPs and a policy of 'backing winners'; instead, what the DMO markets is dictated to by the diverse and sometimes conflicting interests of its various members.

So it is that a 'marketing of everything' approach typifies cities and towns blessed with competitive advantage, as well as those in which it is deficient. Of the 60 European cities and towns enumerated in Table 1 , just 2 cities are marketing CA with content in the vast bulk of the remainder (56) embodying a 'marketing of everything approach'. The remaining two places (Venice and Rome) I have labelled as 'marketing nothing' inasmuch as DMO do not exist in these cities. As Table 1 shows, the DMOs for Innsbruck and Vienna stand out as exceptional due to their marketing of $\mathrm{CA}$, achieved in the case of the Vienna Tourist Board (VTB) by adherence to a Vienna: now or never brand manual in which there is a clear delineation of five competitive advantages (termed brand modules in the manual) of which 'imperial heritage' is uppermost, with music and food/drink also being important. Further specificity in respect of marketing content is achieved through the enumeration of a handful of so-called brand drivers for each of the modules (e.g. Schonbrunn Palace is one such driver of imperial heritage)). In this manner, competitive advantage is made to permeate all aspects of VTB marketing; the manual ensures VTB marketing backs 'winners', determining what is marketed (e.g. Vienna Boys' Choir and the Viennese Waltz as opposed to music in general) and what isn't (e.g. nightlife and shopping). With this high level of CA specificity, marketing operations are then executed on a grand scale, with great innovation, customer focus and creativity, so that in terms of effectiveness and best practice the Board is acknowledged as a DMO 'leader of the pack' (Heeley, 2011, chapter 4). In terms of the theory of marketing CA, the fact that few other DMOs use their brand in this way (i.e. to ensure they rigorously delineate and subsequently market CA) is signal testimony to the prevalence of 'marketing 
of everything' approaches in contemporary Europe.

The final observation I wish to make in this paper relates directly to the conference theme Thematic Tourism in a Global Environment. For 'marketing of everything' read 'theming of urban sameness." If in practice urban destination marketing overwhelmingly fails to address what is unique about a place, then in an age of relentless globalisation it follows that the 'marketing of everything' approaches employed by DMOs presents in toto a uniform imagery of sameness. The author's examination of the promotional videos produced by the destinations listed in Table 1 bears out Turkell and Uysal observations that DMOs deploy remarkably similar imagery. In the case of the videos it is planes landing; trains, trams and subway systems; classical and contemporary art; cafe culture, coffee and cakes and eating out; hotel welcome desks and beds; wine in glasses; clocks, markets, rooftops, and skyscrapers; concerts and theatres; parkland and food markets; and young people dancing and swimming. In this way, 'marketing of everything' reduces to a monolithic and bland 'theming of urban sameness'.

In conclusion, marketing CA is important to success in destination marketing, as noted above in the destination marketing carried out by the Vienna Tourist Board. It is, however, an ideal which is extremely difficult to translate into practice, so much so that effective marketing of CA by DMOs is atypical. Marketing VTB style is the exception rather than the rule. Elsewhere, destination marketing is "much of a muchness". The unpalatable reality for the majority of urban destinations is that they lack real competitive advantage in product terms, and the resultant DMO marketing is typically one which markets all that is pleasant and appealing about the place. Even in those destinations that are blessed with CA, the vast bulk of DMOs in their marketing rarely focus on their USP attributes for re- alpolitik considerations, especially 'he who pays the piper calls the tune' financial considerations. Therefore, and irrespective of whether urban destinations have or do not have competitive advantage, DMO marketing generally embodies a 'marketing of everything' approach which, in turn, translates into a 'theming of sameness', all of which is fundamentally at odds with what one would expect to happen under the theory of marketing CA. For practitioners, there is the worrying implication that in not marketing CA most DMOs are unable to fulfil their core economic and commercial purpose. Of the few that are successful - the DMO 'leaders of the pack' - they succeed precisely because they effectively market genuine CA. For academics, it is now time radically to reappraise destination marketing theory. At present, the academic literature treats marketing $\mathrm{CA}$ as a given and takes insufficient account of how in practice the majority of DMOs do not implement such an approach. The failure to 'tell it like it is' - the yawning gap between theory and practice - warrants in the author's view a substantial rethinking of the paradigm within which we currently seek to explain and otherwise account for destination marketing.

\section{References}

Ashworth, G. and Goodall, B. (1990). Marketing Tourism Places London, Routledge.

Ashworth, G. (2011). "Should we brand places?" Journal of Town and City Management, 1, 3, pp. 248-253.

Boswell, J. (2008). The Life of Samuel Johnson London, Penguin.

Bramwell, B. and Rawding, L. (1994). "Tourism marketing organisations in industrial cities: objectives, organisation and urban governance", Tourism Management, 15, 6, pp. 425-434.

Bramwell, B. and Rawding, L. (1996). "Tourism marketing images of industrial cities", 
Annals of Tourism Research, 23, 1, pp. 201221.

Buhalis, D. (2000). "Marketing the competitive destination of the future", Tourism Management, 21, 1, pp. 97-116.

Cooper, C., Fletcher, J., Fyall, A., Gilbert, D., and Wanhill, S. (eds.) (2008). Tourism: principles and practice, Harlow, Pearson Education.

Cox, C. And Wray, M. (2011). "Best practice marketing for regional tourism destinations", Journal of Travel and Tourism Marketing, 25, 5, pp. 524-540

DMO World Newsletter, 3, March 2005.

Friel, E.J. "Convention market", in Witt, S. and Moutinho, L (eds.) (1989). Tourism Marketing and Management Handbook London, Prentice Hall, pp. 75-77.

Friel, E.J. (2011). "City tourist offices and convention bureaux - who really needs them?" Keynote address at European Cities Marketing Spring Meeting, Sofia, Bulgaria, March.

Fyall, A. and Garrod, B. (2005). Tourism Marketing: a collaborative approach, Bristol, Channel View Publications.

Gilbert, D. (1990). "Strategic marketing planning for national tourism", The Tourist Review, 1, pp. 8-27

Heeley, J. (1982). "Whither the study of tourism in Britain?" Tourism Management, 3, 2, pp. 120-121.

Heeley, J. (1987). "The problematics of urban resort development”, Journal of the Scottish Association of Geography Teachers, 16, pp. 45-50.

Heeley, J. (2011). Inside City Tourism: a European perspective Bristol, Channel View Publications.

International Association of Convention and Visitor Bureaux Fundamentals of Destination Management and Marketing, (2005). Washington, IACVB.

Judd, D.R. (1995). "Promoting tourism in US cities", Tourism Management, 16, 3, pp. 175-187.
Kant, A. (2009). Branding India: an incredible story, Noida, India, Collins Business.

Kavaratzis, M. \& Ashworth, G.J. (2005). “City branding: an effective assertion of identity or a transitory marketing trick?", Tijdschrift voor Economische en Sociale Geografie, 96, 5, pp. 506-514.

Kolb, B.M. (2006). Tourism Marketing for Cities and Towns: using branding and events to attract tourists Oxford, Butterworth-Heinemann.

Kotler, P. et al. (1993). Attracting Investment, Industry, and Tourism to Cities, States and Nations, New York, the Free Press.

Kotler, P. (1997). Marketing Management, Upper Saddle River, New Jersey, PrenticeHall, 1997.

Law, C.M. (1992). "Urban tourism and its contribution to economic regeneration", Urban Studies, 29, 3/4, pp. 599-618

Law, C.M. (2002). Urban Tourism: the visitor economy and the growth of large cities, London, Continuum.

Laws, E. (1995). Tourist Destination Management: issues, analysis and policies, London, Routledge.

Middleton, V.T.C. (1989). “Tourist product” in Witt, S. and Moutinho, L. (eds.) Tourism Marketing and Management Handbook, London, Prentice Hall, pp. 573-576.

Morgan, M. et al. (2008). Destination Branding: creating the unique destination proposition, Oxford, Butterworth-Heinemann.

Maitland, R. and Ritchie, B.W. (eds.) (2009). City Tourism: national capital perspectives, Oxfordshire, CABI.

Page, S. (1995). Urban Tourism, London, Routledge.

Paskaleva-Shapira, K.A. (2007). "New paradigms in city tourism management: redefining tourism promotion", Journal of Travel Research, 46, 1, pp. 108-114.

Pearlman, M. (1989). "Appraising tourism potential” in Witt, S. and Moutinho, L. (eds.) Tourism Marketing and Management Handbook, London, Prentice Hall, pp. 9-14. 
Swarbrooke, J. (2000). “Tourism, economic development and urban regeneration: a critical evaluation", Robinson, M. et al (eds.) in Developments in Urban and Rural Tourism, Sunderland, Centre for Travel and Tourism, pp. 269-285.

Thomas, R. (2011). "Academics as policy-makers: (not) researching tourism and events policy formation from the inside", Current Issues in Tourism, 14, 6, pp. 493-506.

Urry, J. (1990). The Tourist Gaze, London, Sage.

Uysal, U.E. (2013). "Urban Tourism Promotion: What Makes the Difference", Current Research Journal of Social Sciences, 5, 1, pp. 17-27.

Witt, S. and Moutinho, L. (eds.) (1989). Tourism Marketing and Management Handbook, London, Prentice Hall, 1989, pp. 573-576. 
